\title{
Etileno e peróxido de hidrogênio na formação de aerênquima em milho tolerante a alagamento intermitente
}

\author{
Marinês Ferreira Pires(1), Evaristo Mauro de Castro(1), Paulo César Magalhães ${ }^{(2)}$, \\ Izabel Costa Silva Neta ${ }^{(1)}$ e Aline Gomes Dias Pinto Monteiro(1)
}

\begin{abstract}
(1)UniversidadeFederaldeLavras,CampusUniversitário,CaixaPostal3037,CEP37200-000Lavras,MG,Brasil.E-mail:marinesfpires@gmail.com, emcastro@dbi.ufla.br, izabel_agronomia@hotmail.com, alinemonteiro@dca.ufla.br (2)Embrapa Milho e Sorgo, Caixa Postal 151, CEP 35701-970 Sete Lagoas, MG, Brasil. E-mail: paulo.magalhaes@embrapa.br
\end{abstract}

\begin{abstract}
Resumo - O objetivo deste trabalho foi avaliar o papel do etileno e do peróxido de hidrogênio $\left(\mathrm{H}_{2} \mathrm{O}_{2}\right)$ na formação do aerênquima em ciclos de seleção genética da cultivar de milho BRS 4154, sob alagamento. Plantas dos ciclos $\mathrm{C} 1$ e $\mathrm{C} 18$ foram submetidas a alagamento por 7 dias, com coleta das raízes aos 0 (controle, sem alagamento), 1 e 7 dias. Foram analisados: a expressão gênica das enzimas ACC sintase (ACS), ACC oxidase (ACO), dismutase do superóxido (SOD) e peroxidase do ascorbato (APX); a produção de etileno e o conteúdo de $\mathrm{H}_{2} \mathrm{O}_{2}$; a atividade da enzima ACO; e a proporção de aerênquima no córtex. Não houve expressão de ACS e ACO. Houve variação na atividade de ACO e na produção de etileno. A expressão da SOD foi maior em plantas $\mathrm{C} 1$ e a da $\mathrm{APX}$, em C18, com redução aos 7 dias. $\mathrm{O}$ conteúdo de $\mathrm{H}_{2} \mathrm{O}_{2}$ não diferiu entre os tratamentos. A proporção de aerênquima aumentou com o tempo, tendo sido maior em plantas $\mathrm{C} 18$ e relacionada à taxa de formação do aerênquima. $\mathrm{O}$ tempo de alagamento e o nível de tolerância do ciclo de seleção influenciam a produção do etileno. A expressão da APX indica maior produção de $\mathrm{H}_{2} \mathrm{O}_{2}$ no início do alagamento.
\end{abstract}

Termos para indexação: Zea mays, anatomia radicular, atividade enzimática, expressão gênica.

\section{Ethylene and hydrogen peroxide in the aerenchyma formation in maize tolerant to intermittent flooding}

\begin{abstract}
The objective of this work was to evaluate the role of ethylene and hydrogen peroxide $\left(\mathrm{H}_{2} \mathrm{O}_{2}\right)$ in the aerenchyma formation in genetic selection cycles of the maize cultivar BRS 4154, under flooding. Plants from cycles $\mathrm{C} 1$ and $\mathrm{C} 18$ were flooded for 7 days, with roots collected at 0 (control, no flooding), 1, and 7 days. The following were evaluated: gene expression of the enzymes ACC synthase (ACS), ACC oxidase (ACO), superoxide dismutase (SOD), and ascorbate peroxidase (APX); ethylene production and $\mathrm{H}_{2} \mathrm{O}_{2}$ content; enzymatic activity of ACO; and aerenchyma proportion in the cortex. There was no expression of ACS and ACO. ACO activity and ethylene production varied. SOD expression was higher in $\mathrm{C} 1$ plants and that of APX in $\mathrm{C} 18$ plants, with reduction at 7 days. $\mathrm{H}_{2} \mathrm{O}_{2}$ content did not differ between treatments. The proportion of aerenchyma increased with time, being higher in $\mathrm{C} 18$ plants and related to the aerenchyma formation rate. The flooding time and the tolerance level of the selection cycle influence ethylene production. The expression of APX indicates greater $\mathrm{H}_{2} \mathrm{O}_{2}$ production at the beginning of flooding.
\end{abstract}

Index terms: Zea mays, root anatomy, enzyme activity, gene expression.

\section{Introdução}

O alagamento do solo é umas das principais restrições à produção agrícola e afeta cerca de $10 \%$ da superfície terrestre (Patel et al., 2014), em razão da redução na concentração de gases no solo, o que resulta em hipoxia ou anoxia (Sairam et al., 2008).

Em plantas tolerantes, uma das estratégias comuns é a formação de aerênquima, um tecido vegetal com alta proporção de espaços intercelulares (Evans, 2004), que facilita a difusão de gases entre os órgãos inundados e não inundados das plantas, o que permite a respiração aeróbica das células radiculares (Yamauchi et al., 2013). De acordo com o mecanismo de formação, esse tecido distingue-se em: esquizógeno, no qual há crescimento diferencial e separação das células com a desmontagem da lamela média (Evans, 2004), sem morte celular; lisígeno, no qual ocorre morte celular e subsequente lise de algumas células (Yamauchi et al., 2013); e expansígeno, formado pela expansão de espaços por meio de divisão e crescimento celular, sem separação das células e com colapso ou morte celular (Seago Jr et al., 2005). 
Em milho (Zea mays L.), uma planta sensível à hipoxia, há formação de aerênquima lisígeno no córtex da raiz, induzida por esse estresse. Nesse contexto, a cultivar BRS 4154, anteriormente denominada BR 4154 (Saracura), é resistente a períodos intermitentes de alagamento, em que o aerênquima é a estrutura fundamental para esta resposta (Pereira et al., 2008, 2010; Souza et al., 2009, 2011).

Para a formação de aerênquima lisígeno em milho, a deficiência de oxigênio estimula a produção de etileno (Geisler-Lee et al., 2010), que regula a produção de espécies reativas de oxigênio (EROs), o que, por sua vez, leva à morte celular programada (Yamauchi et al., 2013). Além disso, há indícios da relação direta entre a formação de EROs e o surgimento do aerênquima (Steffens et al., 2013), uma vez que a produção dessas moléculas, principalmente do peróxido de hidrogênio $\left(\mathrm{H}_{2} \mathrm{O}_{2}\right)$, por complexos enzimáticos, é induzida em condições de hipoxia e pode levar à morte celular (Yamauchi et al., 2013).

OBrasil é o terceiro maior produtor mundial de milho, com 75 milhões de toneladas previstas para 2014/2015 pelo United States Department of Agriculture (Estados Unidos, 2015) e aproximadamente 15 milhões de hectares de área plantada (Acompanhamento..., 2015). No entanto, aproximadamente 28 milhões de hectares de terras com potencial agrícola do País são suscetíveis ao alagamento (Vitorino et al., 2001). Assim, estudos que favoreçam a compreensão dos mecanismos de formação do aerênquima em milho 'BRS 4154' são fundamentais na exploração do potencial de tolerância desta cultivar, que atende a demanda de plantio em regiões de várzea no Brasil.

$\mathrm{O}$ objetivo deste trabalho foi avaliar o papel do etileno e do peróxido de hidrogênio $\left(\mathrm{H}_{2} \mathrm{O}_{2}\right)$ na formação do aerênquima em ciclos de seleção genética da cultivar de milho BRS 4154, sob alagamento.

\section{Material e Métodos}

O material vegetal, disponibilizado pela Embrapa Milho e Sorgo, em Sete Lagoas, MG, consistiu de sementes provenientes de ciclos de seleção anual da cultivar de milho BRS 4154, com níveis contrastantes de tolerância ao alagamento: $\mathrm{C} 1$, menos tolerante; e C18, mais tolerante.

A germinação das sementes ocorreu em 2014, em vasos de 4,0 L, que continham vermiculita expandida em condições de umidade, temperatura e luminosidade ambientes, em casa de vegetação, no Departamento de Ciências do Solo, da Universidade Federal de Lavras. A fertilização foi realizada com solução nutritiva de acordo com Malavolta (1980), no momento do plantio e em duas aplicações posteriores, durante 2 semanas. Irrigação normal foi realizada regularmente, tendo-se mantido a capacidade de vaso. Foram semeadas seis sementes por vaso, com posterior desbaste para quatro plantas no início dos tratamentos.

Os vasos com as plantas no estádio V6 foram alagados, com lâmina de água na altura da primeira folha, durante 7 dias, tendo-se mantido condições acima da capacidade de campo do substrato, com coletas aos 0 (sem alagamento), 1 e 7 dias. A montagem do experimento foi realizada em delineamento inteiramente casualizado, em arranjo fatorial $2 \times 3$ (ciclos de seleção $\mathrm{x}$ tempo de alagamento), com um vaso por parcela e três repetições.

Para a extração do RNA, raízes completas foram maceradas em nitrogênio líquido, com adição do reagente PureLink RNA Plant (Life Technologies, Invitrogen, Carlsbad, CA, EUA), seguindo as especificações do fabricante. Realizou-se eletroforese em gel de agarose 1,5\% corado com GelRed e análise em espectrofotômetro NanoVue (GE Healthcare Life Sciences, São Paulo, SP), para avaliar a integridade e a pureza do RNA. Em seguida, as amostras foram tratadas com DNase-Free, com uso do kit Ambion DNase-Free (Life Technologies, Invitrogen, Carlsbad, CA, EUA), de acordo com as recomendações do fabricante. A eficiência do tratamento com DNAse foi comprovada por reação de PCR convencional, tendo-se utilizado como controle positivo todas as amostras do milho e o iniciador correspondente ao gene ubiquitina.

Realizou-se a síntese de cDNA com uso do kit High Capacity cDNA Reverse Transcription cDNA (Applied Biosystems, Life Technologies, Carlsbad, CA, EUA), seguindo o protocolo do fabricante. Os iniciadores foram selecionados com base em Gallie et al. (2009) e Geisler-Lee et al. (2010) (Tabela 1), tendo-se considerado duas enzimas da rota biossintética do etileno: ácido 1-carboxílico-1-aminociclopropano (ACC) sintase (ACS) (EC 4.4.1.14) e oxidase (ACO) (EC 1.14.17.4); e duas enzimas do sistema antioxidante: dismutase do superóxido (SOD) (EC 1.15.1.1) e peroxidase do ascorbato (APX) (EC 
1.11.1.11), importantes no mecanismo de remoção do excesso de espécies reativas de oxigênio (EROs).

A qRT-PCR foi realizada por meio do real-time PCR System 7500 (Applied Biosystems, Life Technologies, Carlsbad, CA, EUA), com uso do SYBR Green PCR Master Mix (Applied Biosystems, Life Technologies, Carlsbad, CA, EUA) e das amostras de cDNAs sintetizadas. As condições térmicas da reação foram: 2 min a $50^{\circ} \mathrm{C}$; $10 \mathrm{~min}$ a $95^{\circ} \mathrm{C}$, seguidos de 40 ciclos de $15 \mathrm{~s}$ a $95^{\circ} \mathrm{C}$; e $1 \mathrm{~min}$ a $60^{\circ} \mathrm{C}$; e, ao final, $15 \mathrm{~s} \mathrm{a}$ $95^{\circ} \mathrm{C}$. Os dados foram coletados e armazenados no programa 7500 Fast, versão 2.1 (Applied Biosystems, Life Technologies, Carlsbad, CA, EUA). Os controles negativos (água) e endógenos foram incluídos em todas as análises, realizadas em triplicatas. Os resultados foram normalizados com uso do "cycle threshold" (CT), ou seja, do ciclo limiar, obtidos pela expressão do gene de referência ubiquitina. O CT foi determinado pelo número de ciclos no qual a fluorescência gerada dentro de uma reação cruza a linha de base ("threshold"). Foi utilizado o método do CT comparativo. As curvas padrões para os genes em estudo foram geradas a partir das seguintes diluições: $1: 5,1: 25,1: 125,1: 625$ e 1:3125. Este procedimento também permitiu a definição da melhor diluição de cDNA utilizada em cada reação, a qual foi de 1:5. As amostras de menor expressão, para cada gene, foram utilizadas como amostras calibradoras, e o método utilizado para medir a expressão relativa foi o método da curva padrão relativo, descrito no manual do aparelho (Applied Biosystems, Life Technologies, Carlsbad, CA, EUA). Para calcular o nível de expressão dos genes de interesse, foram considerados: $\mathrm{Ct}$, aumento exponencial do produto de PCR do gene alvo e controle endógeno; $\Delta \mathrm{Ct}=\mathrm{Ct}$ (amostra) - $\mathrm{Ct}$ (controle endógeno); e $\Delta \Delta \mathrm{Ct}=\Delta \mathrm{Ct}$ (amostra) $-\Delta \mathrm{Ct}$ (calibrador). Em seguida, o nível de expressão foi calculado pela fórmula: $\mathrm{RQ}=2^{-\Delta \Delta \mathrm{Ct}}$.

A atividade enzimática de ACC oxidase foi determinada por meio da produção de etileno após 1 hora de incubação de uma solução com extrato das raízes e de ACC. O processo de extração foi modificado a partir de Britsch \& Grisebach (1986), em que $0,5 \mathrm{~g}$ de material vegetal fresco (raízes completas) foi macerado com nitrogênio líquido e solução tampão de extração contendo Tris $0,1 \mathrm{~mol} \mathrm{~L}^{-1}(\mathrm{pH} 7,2)$, glicerol $10 \%(\mathrm{v} / \mathrm{v})$, ascorbato de sódio $30 \mathrm{mmol} \mathrm{L}^{-1}$ e polivinilpolipirrolidona (PVPP) $5 \% \quad(\mathrm{~m} / \mathrm{v})$. Posteriormente, realizou-se centrifugação a $28.000 \mathrm{~g}$, por $20 \mathrm{~min}, \mathrm{a} 4^{\circ} \mathrm{C}$. O sobrenadante foi coletado para o ensaio enzimático.

O ensaio enzimático foi realizado de acordo com Fernández-Maculet \& Yang (1992), com modificações, em que foram adicionados $1,7 \mathrm{~mL}$ da solução tampão de extração (sem PVPP), $\mathrm{FeSO}_{4} 50 \mu \mathrm{mol} \mathrm{L}^{-1}$ e ACC 1,0 $\mathrm{mmol} \mathrm{L}^{-1}$ a $0,2 \mathrm{~mL}$ do extrato. Em seguida, foi realizada incubação em banho-maria a $30^{\circ} \mathrm{C}$, por 1 hora, em tubos vedados. Amostras de $10 \mathrm{~mL}$ da atmosfera interna de cada tubo foram coletadas com auxílio de seringa Gastight (Hamilton Storage Technologies, Franklin, MA, EUA) e transferidas para tubos de vácuo timer (CK, São Paulo, SP). Posteriormente, a concentração de etileno produzida foi determinada com uso de cromatógrafo gasoso CG-2010 Plus (Shimadzu do Brasil, São Paulo, SP), com detector de ionização de chamas e coluna Carboxen (50946-03A). As condições utilizadas na análise foram: sistema de injeção splitless; volume de injeção de $10 \mathrm{~mL}$; temperatura do injetor de

Tabela 1. Sequências dos iniciadores utilizados na análise de qRT-PCR em raízes de milho (Zea mays) 'BRS 4154' submetidas ao alagamento ${ }^{(1)}$.

\begin{tabular}{|c|c|c|c|c|c|}
\hline Gene & Identificação & & Sequência 5 & -- & $----3^{\prime}$ \\
\hline $\mathrm{ZmACS} 2$ & ACC sintase & $\mathrm{F}$ & ATCGCGTACAGCCTCTCCAAGGA & $\mathrm{R}$ & GATAGTCTTTTGTCAACCATCCCATAGA \\
\hline ZmACS6 & ACC sintase & $\mathrm{F}$ & AGCTGTGGAAGAAGGTGGTCTTCGAGGT & $\mathrm{R}$ & AGTACGTGACCGTGGTTTCTATGA \\
\hline $\mathrm{ZmACS} 7$ & ACC sintase & $\mathrm{F}$ & ATCGCGTACAGCCTCTCCAAGGA & $\mathrm{R}$ & CAACGTCTCTGTCACTCTGTGTAATGT \\
\hline $\mathrm{ZmACO} 15$ & ACC oxidase & $\mathrm{F}$ & CTCGTCTTCGATCAATTCCCAAGT & $\mathrm{R}$ & TACATTATCATTATTTCTCCGGCTGT \\
\hline $\mathrm{ZmACO} 20$ & ACC oxidase & $\mathrm{F}$ & CTCATCCTGCTGCTCCAGGACGAC & $\mathrm{R}$ & TCCACGATACACGCATAACCACCGT \\
\hline $\mathrm{ZmACO} 31$ & ACC oxidase & $\mathrm{F}$ & CTCGTCTTCGATCAATTCCCAAGT & $\mathrm{R}$ & ATAGCAAAGAGGGCAACTAGCTAGT \\
\hline $\mathrm{ZmACO} 35$ & ACC oxidase & $\mathrm{F}$ & CTCATCCTGCTGCTCCAGGACGAC & $\mathrm{R}$ & ACACACATAACTGTGCCACTATAAGCA \\
\hline Ubiquitina (UBI) ${ }^{(2)}$ & Controle endógeno & $\mathrm{F}$ & GTCAGTAAGTCATGGGTCGT & $\mathrm{R}$ & ACA TAATGAGCACAGGCTTT \\
\hline SOD4 $4^{(2)}$ & Dismutase do superóxido & $\mathrm{F}$ & TGGAGCACCAGAAGATGA & $\mathrm{R}$ & CTCGTGTCCACCCTTTCC \\
\hline $\mathrm{cAPX}^{(2)}$ & Peroxidase do ascorbato & $\mathrm{R}$ & TGAGCGACCAGGACATTG & $\mathrm{F}$ & GAGGGCTTTGTCACTTGGT \\
\hline
\end{tabular}

${ }^{(1)} \mathrm{F}$, sequência do iniciador direto; R, sequência do iniciador inverso. ${ }^{(2)}$ Iniciadores que amplificaram nas raízes de milho 'BRS 4154' nas condições estudadas. 
$150^{\circ} \mathrm{C}$; temperatura do detector de $245^{\circ} \mathrm{C}$; temperatura do forno de $150^{\circ} \mathrm{C}$; e gases $\mathrm{H}_{2}$, ar sintético e $\mathrm{N}_{2}$, com

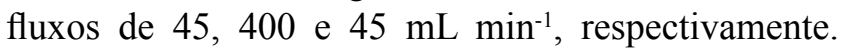
A rampa de aquecimento utilizada foi de $120^{\circ} \mathrm{C}$ por $1 \mathrm{~min}$, mais $25^{\circ} \mathrm{C}$ até $230^{\circ} \mathrm{C}$ por $5 \mathrm{~min}$, com tempo total da corrida de 10,40 min. No cálculo da produção de etileno, levou-se em consideração a massa fresca das raízes e o tempo de acúmulo de etileno. Os resultados foram expressos em $\mu \mathrm{L} \mathrm{C}_{2} \mathrm{H}_{4} \mathrm{~h}^{-1} \mathrm{~kg}^{-1}$.

A determinação da produção de etileno pelas raízes foi realizada de acordo com Geisler-Lee et al. (2010), com modificações: raízes completas, destacadas, foram pesadas em balança analítica e colocadas em frascos de vidro com cerca de $0,5 \mathrm{~mL}$ de água deionizada. Os frascos foram vedados e incubados durante 2 horas. Com auxílio de seringa Gastight (Hamilton Storage Technologies, Franklin, MA, EUA), foram coletados $10 \mathrm{~mL}$ da atmosfera interna de cada frasco (amostra), que foi transferida para tubos de vácuo timer $(\mathrm{CK}$, São Paulo, SP) de $10 \mathrm{~mL}$. A produção de etileno foi determinada como descrito anteriormente.

$\mathrm{O}$ conteúdo de $\mathrm{H}_{2} \mathrm{O}_{2}$ foi obtido de acordo com Velikova et al. (2000). Para a extração, $200 \mathrm{mg}$ de tecido vegetal fresco (raízes completas) foram macerados em nitrogênio líquido, homogeneizados em $1,5 \mathrm{~mL}$ de ácido tricloroacético (TCA) $0,1 \%$ e centrifugados a $12.000 \mathrm{~g}$ por $15 \mathrm{~min}, \mathrm{a} 4^{\circ} \mathrm{C}$.

Em seguida, adicionou-se a $45 \mu \mathrm{L}$ de extrato um meio de reação que continha $45 \mu \mathrm{L}$ de tampão fosfato de potássio $10 \mathrm{mmol} \mathrm{L}^{-1}(\mathrm{pH} 7)$ e $90 \mu \mathrm{L}$ de iodeto de potássio $1,0 \mathrm{~mol} \mathrm{~L}^{-1}$. A determinação do conteúdo de $\mathrm{H}_{2} \mathrm{O}_{2}$ ocorreu por meio da leitura da absorbância em 390 nm e da elaboração de curva-padrão de calibração construída a partir de solução de $\mathrm{H}_{2} \mathrm{O}_{2} 250 \mu \mathrm{mol} \mathrm{L}{ }^{-1}$, com $\mathrm{R}^{2}=0,9932$.

Para as análises anatômicas, raízes completas foram fixadas em solução de formaldeído, ácido acético e etanol a 70\% (FAA) por 72 horas e, então, preservadas em etanol a $70 \%$. Para as análises, o material foi submetido a uma série etanólica crescente para desidratação $(70,80,90$ e 100\%), em temperatura ambiente, de acordo com Johansen (1940), com modificações. Posteriormente, o material foi imerso, por 24 horas, em solução de pré-infiltração, composta por etanol $100 \%$ e resina base $(1: 1)$, tendose utilizado o kit HistoResin (Leica Microsystems, Heidelberg, Alemanha), seguindo as instruções do fabricante. Após esse período, realizou-se a infiltração em resina base por mais 24 horas, a $4^{\circ} \mathrm{C}$. Para a polimerização, também foi utilizado o kit HistoResin (Leica Microsystems, Heidelberg, Alemanha). Secções transversais (fragmentos de 1,0 cm removidos a partir de $10 \mathrm{~cm}$ do ápice) foram realizadas em micrótomo rotativo semiautomático, em espessura de $8 \mu \mathrm{m}$, e, em seguida, coradas em solução de azul de toluidina $1 \%$, pH 6,7 (Feder \& O’Brien, 1968).

As lâminas foram fotografadas com câmeraAxioCam Erc 5s (Zeiss, Oberkochen, Alemanha) acoplada ao microscópio Axio Lab.A1 (Zeiss, Oberkochen, Alemanha), e as análises de micromorfometria foram realizadas no programa de análise de imagens Image Tool, versão 3.0 (University of Texas Health Science Center, San Antonio, TX, EUA). Foi confeccionada uma lâmina por repetição, nas quais seis campos de observação foram analisados e fotografados. A proporção da área ocupada pelo aerênquima no córtex foi calculada com base na divisão da área total de aerênquima formado pela área total do córtex.

Para estimar a taxa de formação de aerênquima (TFA) ao longo do tempo, considerou-se a proporção de aerênquima, tendo como base a equação da taxa de crescimento absoluto, TFA $=\mathrm{PA}_{2}-\mathrm{PA}_{1} / \mathrm{t}_{2}$ (Benincasa, 2003), em que PA é a proporção de aerênquima; $t$ é o tempo em dias; e 1 e 2 são as amostras sucessivas.

Foram calculados a média e o desvio-padrão para todas as variáveis analisadas. A normalidade dos dados foi verificada pelo teste de Shapiro-Wilk, e a transformação $\ln (\mathrm{x})$ foi aplicada aos dados sem distribuição normal.

Os dados foram submetidos à análise de variância, e as médias foram testadas pelo teste de Scott-Knott, a 5\% de probabilidade, com auxílio do programa estatístico Sisvar (Universidade Federal de Lavras, Lavras, MG).

\section{Resultados e Discussão}

Os genes de ACS (EC 4.4.1.14) e ACO (EC 1.14.17.4) não foram expressos nas condições experimentais avaliadas e com as concentrações das amostras e dos iniciadores utilizadas, embora a extração com PureLink RNA Plant tenha gerado RNAs totais de qualidade, íntegros e livres de impurezas, e a amplificação, com uso dos iniciadores do gene constitutivo, tenha mostrado alta viabilidade dos cDNAs construídos. Como a codificação dos genes dessas enzimas pode ser diferencialmente regulada por uma complexa rede de sinais ambientais e de 
desenvolvimento (Vandenbussche et al., 2012), podese inferir que, nas condições analisadas, a expressão das sequências selecionadas não foi estimulada. Fatores epigenéticos podem ter influenciado os níveis de expressão, o que pode ter levado à inativação do gene por inibição da transcrição ou do acúmulo do RNAm. Esse fenômeno, denominado silenciamento de genes, pode ser influenciado pelo local de inserção do transgene e está associado à metilação do DNA receptor, às variações de histonas e às modificações pós-traducionais de histonas (Chinnusamy \& Zhu, 2009). A expressão desses genes foi constatada por Geisler-Lee et al. (2010), ao analisar raízes de milho da linhagem B73 (sensível ao estresse hídrico) expostas a $4 \%$ de oxigênio, o que pode ser atribuído à cultivar e às condições experimentais.

Em relação à atividade de ACO (Figura 1), não houve interação entre os fatores tempo de alagamento

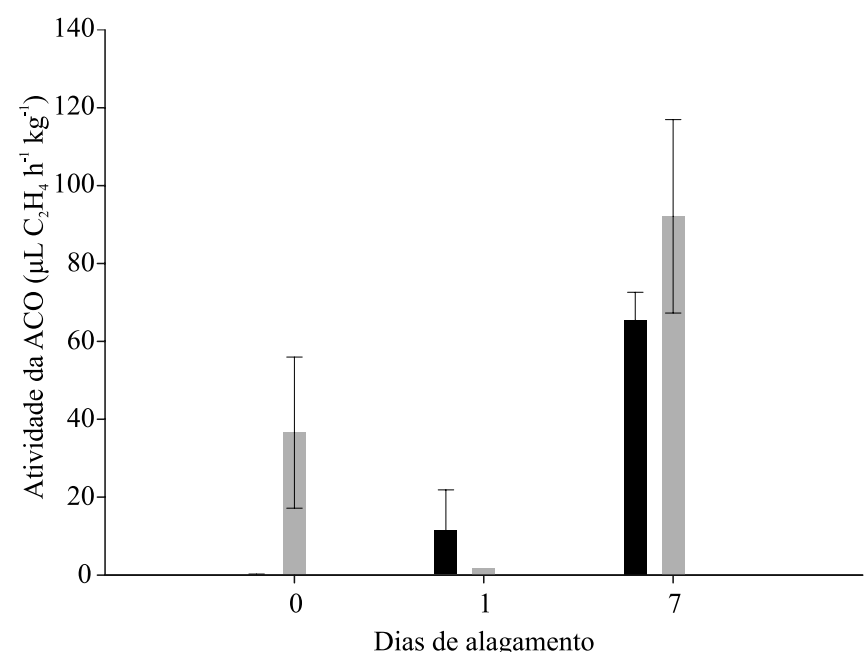

Figura 1. Atividade enzimática da $\mathrm{ACC}$ oxidase em raízes de milho (Zea mays) BRS 4154, nos ciclos de seleção C1 e C18, submetidas ao alagamento, determinada por meio da produção de etileno após 1 hora de incubação. As barras indicam erro-padrão da média. e ciclo de seleção. Verificou-se, no entanto, maior atividade aos 7 dias de alagamento, o que evidencia a participação dessa enzima no processo de formação de aerênquima lisígeno induzido por hipoxia, como relato por Yamauchi et al. (2013). Apesar da expressão dos genes da enzima ACO não ter sido detectada, sua atividade foi afetada pelo alagamento. Às vezes, os resultados obtidos em análises de transcriptômica não coincidem com os da análise proteômica. Dessa forma, uma mesma proteína pode ser codificada por diferentes sequências de nucleotídeos. Conforme D'Onofrio \& Abel (2014), duas linhas independentes coexistem na mesma sequência de nucleotídeos, em decorrência da redundância do código genético. Para estes autores, ter múltiplos códigos de códons que prescrevam o mesmo aminoácido permite que qualquer dessas prescrições redundantes tenha uma codificação alternativa, que pode produzir funções diferentes. No presente trabalho, analisou-se apenas uma sequência de nucleotídeos para cada RNAm, o que pode ter contribuído para os resultados observados, uma vez que outras sequências podem participar na codificação de ACO.

Os resultados de produção de etileno não mostraram interação entre as variáveis tempo e ciclo de seleção. Observou-se aumento na produção de etileno em condições alagadas (Tabela 2), que foi maior em plantas C18 no primeiro dia e em plantas $\mathrm{C} 1$ no sétimo dia de avaliação. Assim, embora C18 não tenha apresentado a maior produção de etileno, esta foi estimulada mais rapidamente, o que pode representar adaptação para tolerância ao alagamento. Geisler-Lee et al. (2010), ao avaliar raízes de milho da linhagem B73 submetidas a $4 \%$ de oxigênio, constataram aumento na produção de etileno por até 12 horas da imposição dos tratamentos, mas redução a partir de 24 horas. No entanto, segundo esses autores, a formação continuada de aerênquima por pelo menos 4 dias é indicação de que a síntese de etileno estava em curso durante esse período. De modo semelhante, houve redução na produção de etileno

Tabela 2. Produção de etileno e conteúdo de peróxido de hidrogênio em raízes de milho (Zea mays) 'BRS 4154' submetidas ao alagamento por 0,1 e 7 dias $^{(1)}$.

\begin{tabular}{|c|c|c|c|c|c|c|}
\hline \multirow[t]{2}{*}{ Ciclos de seleção } & \multicolumn{3}{|c|}{ Produção de etileno $\left(\mu \mathrm{L} \mathrm{C}_{2} \mathrm{H}_{4} \mathrm{~h}^{-1} \mathrm{~kg}^{-1}\right)$} & \multicolumn{3}{|c|}{ Peróxido de hidrogênio (nmol $\mathrm{H}_{2} \mathrm{O}_{2} \mathrm{mg}^{-1}$ de $\mathrm{MF}$ ) } \\
\hline & $0 \mathrm{dia}$ & $1 \mathrm{dia}$ & 7 dias & 0 dia & $1 \mathrm{dia}$ & 7 dias \\
\hline$\overline{\mathrm{C} 1}$ & $0,00 \pm 0,00$ & $4,22 \pm 0,47$ & $469,10 \pm 278,24$ & $0,28 \pm 0,00$ & $0,25 \pm 0,00$ & $0,37 \pm 0,10$ \\
\hline $\mathrm{C} 18$ & $0,00 \pm 0,00$ & $271,38 \pm 268,09$ & $107,77 \pm 52,04$ & $0,27 \pm 0,03$ & $0,24 \pm 0,02$ & $0,29 \pm 0,03$ \\
\hline
\end{tabular}

MF, matéria fresca. 
nas raízes de $\mathrm{C} 18$ aos 7 dias, enquanto a indução de aerênquima permaneceu.

$\mathrm{O}$ aumento na atividade de $\mathrm{ACO}$ em $\mathrm{C} 1$ no início do alagamento foi acompanhado pelo aumento na produção de etileno ao longo do tempo. Em C18, enquanto a atividade enzimática apresentou redução no primeiro dia e aumento no sétimo dia de alagamento, a produção de etileno aumentou no início do alagamento e reduziu ao final do período avaliado. Nesse caso, pode-se concluir que a produção de etileno inicial foi resultado da maior atividade da enzima nos momentos iniciais do alagamento. Nesse sentido, Geisler-Lee et al. (2010) verificaram aumento na produção de etileno em raízes de milho a partir de 3 horas de exposição a $4 \%$ de oxigênio. No entanto, no presente trabalho, não foram avaliadas a produção de etileno e a atividade de ACO nos momentos iniciais. Em relação à queda na produção de etileno em $\mathrm{C} 18$, é possível que a concentração de ACC como substrato possa ter sido um fator limitante, uma vez que a atividade de ACO foi alta. Vandenbussche et al. (2012) afirmaram que a atividade de ACO pode ser indicativa da produção de etileno; porém, esta dependerá, também, da presença de ACC.

Quanto à expressão da SOD e da APX, houve variação entre os ciclos de seleção ao longo do tempo de alagamento (Figura 2). Quando se considera o ciclo de seleção, a expressão da SOD foi maior em $\mathrm{C} 1$, enquanto a da APX foi maior em $\mathrm{C} 18$. Em relação ao tempo de alagamento, houve aumento da expressão em SOD e APX após 1 dia, com posterior redução em 7 dias de hipoxia.

A SOD é considerada a primeira linha de defesa contra níveis elevados de EROs, por remover íon superóxido $\left(\mathrm{O}_{2}{ }^{\circ}\right)$ e por catalizar sua dismutação em $\mathrm{H}_{2} \mathrm{O}_{2}$ e $\mathrm{O}_{2}$ (Gill \& Tuteja, 2010). Em razão do estresse provocado pelo alagamento e da menor tolerância de $\mathrm{C} 1$, pode-se inferir que, nessas plantas, a maior expressão da SOD representou resposta de defesa contra os danos provocados pelo $\mathrm{O}_{2}{ }^{-}$, a qual não foi observada em C18. Quanto ao tempo de alagamento, Porto et al. (2013) constataram redução na expressão de SOD em mesocótilo de plantas C18 alagadas por até 7 dias. Isso mostra que a SOD pode apresentar variações em sua expressão e sintetizar diferentes números de isoformas de acordo com o tecido, a espécie e o tipo de estresse (Zanandrea et al., 2009).
A enzima APX desempenha um dos papéis mais importantes na eliminação de EROs e na proteção das células vegetais, por atuar sobre $\mathrm{o}_{2} \mathrm{O}_{2}$, com formação de água (Gill \& Tuteja, 2010). A sua maior expressão em $\mathrm{C} 18$ pode ser indício de aumento na produção de $\mathrm{H}_{2} \mathrm{O}_{2}$, que, possivelmente, participe nos processos de sinalização, para formação de aerênquima por meio de morte celular programada. Entretanto, a redução de sua atividade aos 7 dias de alagamento provavelmente resultou na menor produção de $\mathrm{H}_{2} \mathrm{O}_{2}$, em virtude da redução no número de células do córtex radicular pela formação do aerênquima. Condições
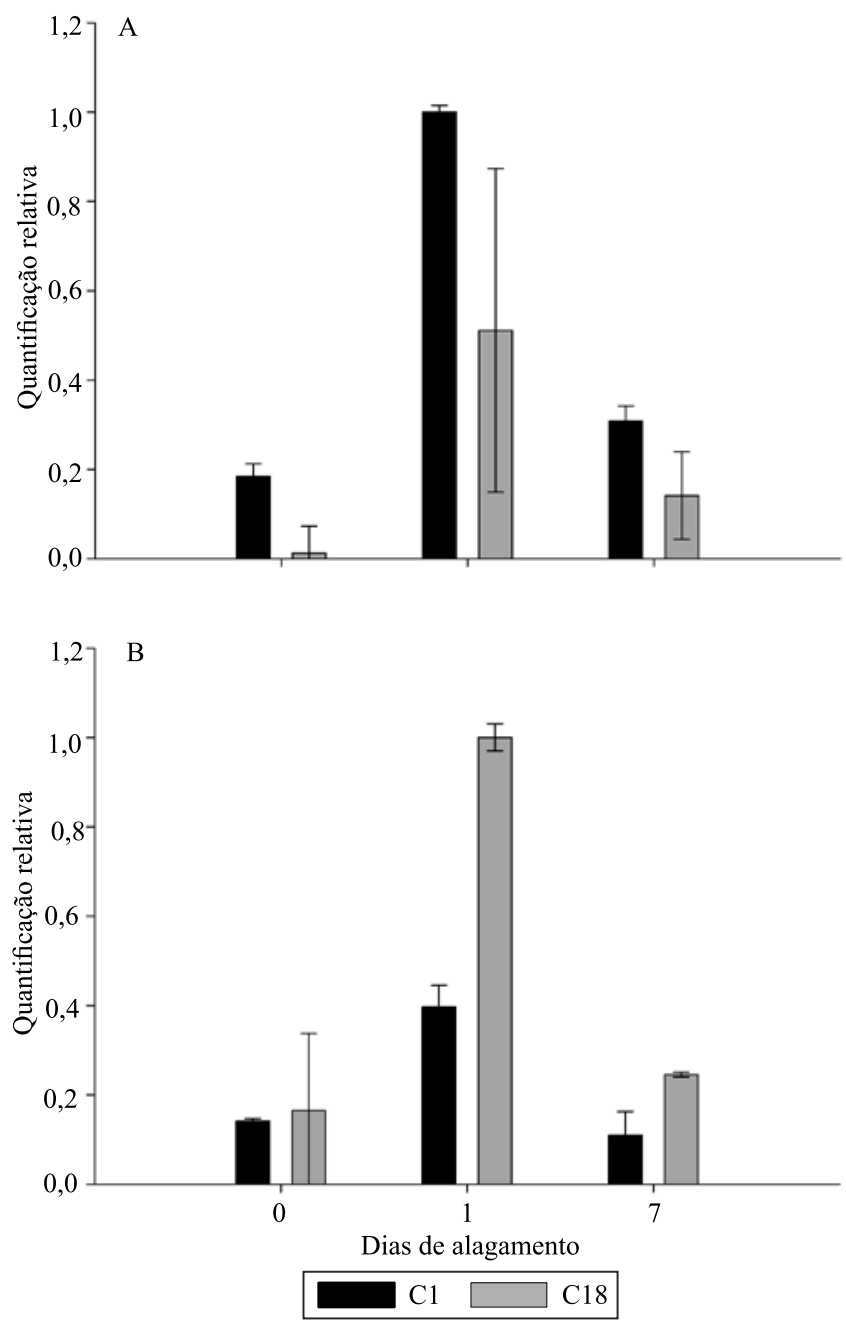

Figura 2. Perfil da expressão relativa quantitativa dos genes SOD4 (A) e cAPX (B) em raízes de milho (Zea mays) 'BRS 4154', nos ciclos de seleção C1 e C18, submetidas ao alagamento. As barras indicam erro-padrão. 
de hipoxia estimulam a produção de $\mathrm{H}_{2} \mathrm{O}_{2}$ (Blokhina et al., 2003). Segundo estes autores, o acetaldeído normalmente acumulado sob essas condições pode funcionar como doador de elétrons e ativar o $\mathrm{O}_{2}{ }^{*-}$ que, ao sofrer dismutação pela ação da SOD, forma $\mathrm{H}_{2} \mathrm{O}_{2}$, cujo conteúdo nas células é regulado pela ação da catalase e por diversas peroxidases, entre elas a APX. Além disso, essas moléculas podem ser geradas por complexos enzimáticos (Apel \& Hirt, 2004).

Em milho 'BRS 4154', sugere-se que o papel das EROs seja importante na formação de aerênquima (Steffens et al., 2013), já que as moléculas avaliadas seriam produzidas pelas plantas em resposta à hipoxia, o que seria uma alternativa ao aumento na produção de etileno, como estratégia de maior tolerância ao alagamento.

Não houve interação entre as variáveis tempo e ciclo de seleção para o conteúdo de $\mathrm{H}_{2} \mathrm{O}_{2}$ nas raízes (Tabela 2); portanto, não houve diferença significativa entre os tratamentos. A ausência de variação na produção de $\mathrm{H}_{2} \mathrm{O}_{2}$ pode ser resultado da redução no número de células corticais radiculares, em razão da formação de aerênquima na condição alagada e da possível ação da APX em $\mathrm{C} 1$ e $\mathrm{C} 18$ após 24 horas de alagamento. Pereira et al. (2010) relacionaram o aumento na proporção de aerênquima no córtex radicular de milho 'BRS 4154' a uma menor produção de EROs nos ciclos finais de seleção, uma vez que haveria melhor difusão de $\mathrm{O}_{2}$ pela raiz, o que resultaria em menor produção de $\mathrm{H}_{2} \mathrm{O}_{2}$. Além disso, a formação de espaços de ar em decorrência do desenvolvimento de aerênquimas reduz a quantidade de células e, consequentemente, os locais de produção de EROs, o que pode ter ocorrido no presente trabalho.

Quanto à proporção de aerênquima, houve interação significativa entre as variáveis, com aumento ao longo do tempo e maior proporção em C18 (Tabela 3 e Figura 3). As variações observadas na proporção de aerênquima entre os ciclos de seleção podem ser relacionadas à TFA, que foi obtida a partir do segundo dia de avaliação.

A maior TFA ocorreu nas primeiras 24 horas de alagamento em todas as plantas analisadas, tendo sido maior em $\mathrm{C} 18$, ciclo com maior potencial de tolerância (Figura 4). Em seguida, a TFA apresentou redução em $\mathrm{C} 1$, enquanto, em $\mathrm{C} 18$, continuou a crescer. De modo semelhante, Pereira et al. (2008, 2010) e Souza et al. (2009) verificaram aumento na proporção de aerênquima no córtex radicular do milho 'BRS 4154', com maior capacidade de desenvolver aerênquima nos últimos ciclos de seleção, quando comparado ao grupo controle e aos ciclos anteriores de seleção. Contudo, o tempo de exposição ao alagamento, a fase de desenvolvimento das plantas e as condições experimentais foram diferentes dos utilizados no presente trabalho. Apesar disso, o maior desenvolvimento de aerênquima nas raízes do milho 'BRS 4154', principalmente nos ciclos finais, foi uma resposta comum entre os estudos.

O maior incremento na TFA com 1 dia de alagamento coincidiu com a maior expressão de APX, provavelmente relacionada a uma elevação na produção de $\mathrm{H}_{2} \mathrm{O}_{2}$ nesse momento, o que indica participação dessa molécula na formação inicial de aerênquima. $\mathrm{O}$ aumento na produção de etileno em $\mathrm{C} 18$ também foi evidente nesse período, o que mostra que o hormônio pode ser relacionado à indução de aerênquima no ciclo

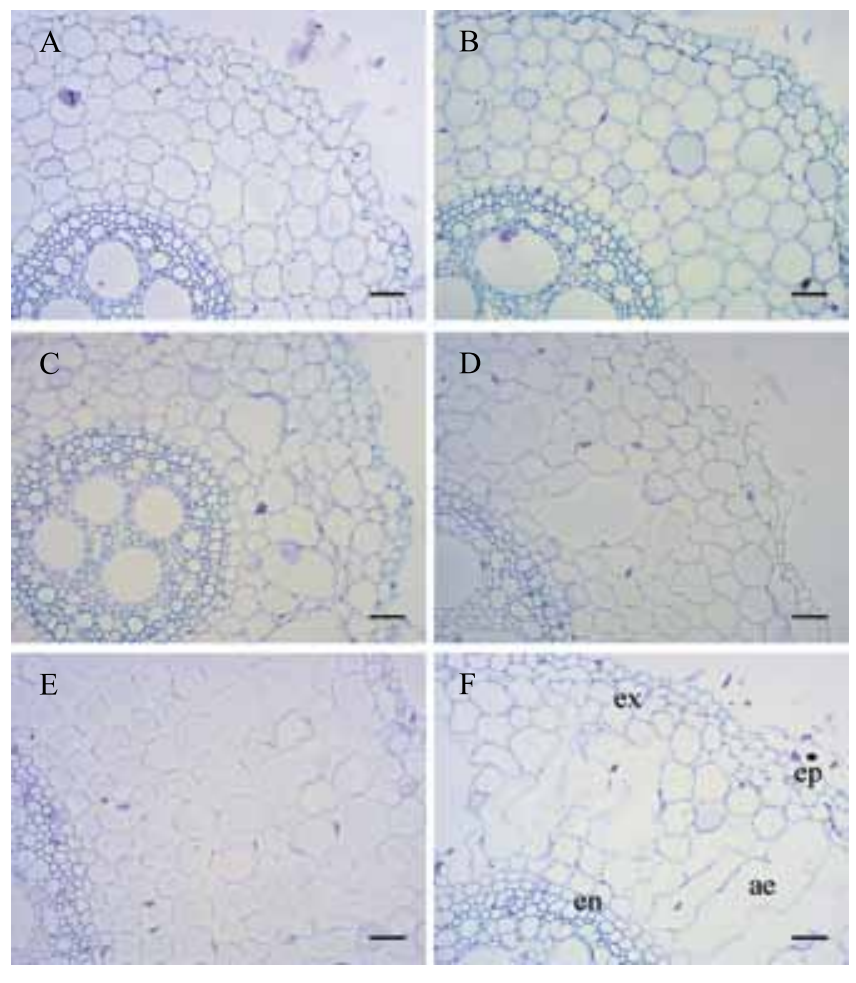

Figura 3. Secções transversais de raízes de milho (Zea mays) que evidenciam a proporção de aerênquima no córtex. Ciclos de seleção C1 (A, C, E) e C18 (B, D, F), submetidos a 0 (A, $\mathrm{B}), 1(\mathrm{C}, \mathrm{D})$ e 7 (E, F) dias de alagamento. ae, aerênquima; en, endoderme; ep, epiderme; ex, exoderme. Barras $=50 \mu \mathrm{m}$. Aumento de 20x. 
Tabela 3. Proporção de área ocupada por aerênquima em relação à área total do córtex radicular de ciclos de seleção de milho (Zea mays) 'BRS 4154' submetido ao alagamento por 0,1 e $7 \operatorname{dias}^{(1)}$.

\begin{tabular}{lcccc}
\hline Ciclos de seleção & \multicolumn{3}{c}{ Área ocupada pelo aerênquima (\%) } & \multirow{2}{*}{ Média } \\
\cline { 2 - 4 } & 0 dia & 1 dia & 7 dias & \\
\hline C1 & $0,57 \mathrm{Ab}$ & $7,54 \mathrm{Ba}$ & $6,34 \mathrm{Ba}$ & $4,82 \mathrm{~B}$ \\
$\mathrm{C} 18$ & $0,45 \mathrm{Ac}$ & $14,96 \mathrm{Ab}$ & $42,79 \mathrm{Aa}$ & $19,40 \mathrm{~A}$ \\
\hline Média & $0,51 \mathrm{c}$ & $11,09 \mathrm{~b}$ & $24,57 \mathrm{a}$ & \\
\hline
\end{tabular}

(1)Médias seguidas de letras iguais, minúsculas nas linhas e maiúsculas nas colunas, não diferem pelo teste de Scott-Knott, a 5\% de probabilidade.

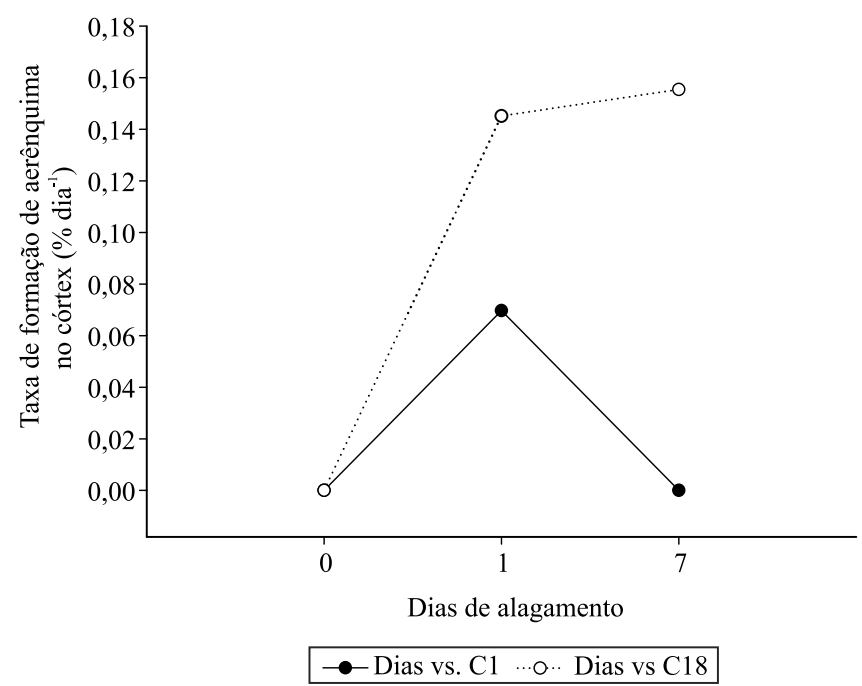

Figura 4. Taxa de formação de aerênquima em raízes de ciclos de seleção de milho (Zea mays) 'BRS 4154', em relação ao tempo de alagamento.

mais tolerante. Porém, o contínuo aumento na TFA em $\mathrm{C} 18$ pode ser resultante da maior sensibilidade das células ao etileno, como resposta de maior tolerância ao alagamento.

\section{Conclusões}

1. O tempo de alagamento e o nível de tolerância do ciclo de seleção genética influenciam a produção do etileno, na via de sinalização para indução de aerênquima lisígeno em milho (Zea mays) 'BRS 4154'.

2. A expressão da peroxidase do ascorbato indica maior produção de peróxido de hidrogênio no início do alagamento.

\section{Agradecimentos}

À Fundação de Amparo à Pesquisa do Estado de Minas Gerais (Fapemig), pela concessão de bolsa; e ao Conselho Nacional de Desenvolvimento Científico e Tecnológico $(\mathrm{CNPq})$, pelo apoio financeiro.

\section{Referências}

ACOMPANHAMENTO da safra brasileira: grãos. Safra 2014/15, quarto levantamento. Brasília, DF: Conab, 2015. Disponível em: $<$ http://www.conab.gov.br/>. Acesso em: 10 maio 2015.

APEL, K.; HIRT, H. Reactive oxygen species: metabolism, oxidative stress, and signal transduction. Annual Review of Plant Biology, v.55, p.373-399, 2004. DOI: 10.1146/annurev. arplant.55.031903.141701.

BENINCASA, M.M.P. Análise de crescimento de plantas: noções básicas. Jaboticabal: Funep, 2003. 42p.

BLOKHINA, O.; VIROLAINEN, E.; FAGERSTEDT, K.V. Antioxidants, oxidative damage and oxygen deprivation stress: a review. Annals of Botany, v.91, p.179-194, 2003. DOI: 10.1093/ $\mathrm{aob} / \mathrm{mcf1} 18$.

BRITSCH, L.; GRISEBACH, H. Purification and characterization of (2S)-flavanone 3-hydroxylase from Petunia hybrida. European Journal of Biochemistry, v.156, p.569-577, 1986. DOI: 10.1111/ j.1432-1033.1986.tb09616.x.

CHINNUSAMY, V.; ZHU, J.-K. Epigenetic regulation of stress responses in plants. Current Opinion in Plant Biology, v.12, p.133-139, 2009. DOI: 10.1016/j.pbi.2008.12.006.

D'ONOFRIO, D.J.; ABEL, D.L. Redundancy of the genetic code enables translational pausing. Frontiers in Genetics, v.5, article 140, 2014. DOI: 10.3389/fgene.2014.00140.

ESTADOS UNIDOS. Department of Agriculture. World agricultural supply and demand estimates report (WASDE). Washington, 2015. Available at: <http://www.usda.gov/oce/ commodity/wasde/>. Accessed on: 6 Feb. 2015.

EVANS, D.E. Aerenchyma formation. New Phytologist, v.161, p.35-49, 2004. DOI: 10.1046/j.1469-8137.2003.00907.x.

FEDER, N.; O'BRIEN, T.P. Plant microtechnique: some principles and new methods. American Journal of Botany, v.55, p.123-142, 1968. DOI: $10.2307 / 2440500$.

FERNÁNDEZ-MACULET, J.C.; YANG, S.F. Extraction and partial characterization of the ethylene-forming enzyme from apple fruit. Plant Physiology, v.99, p.751-754, 1992. DOI: 10.1104/ pp.99.2.751.

GALLIE，D.R.; GEISLER-LEE，J.; CHEN，J.; JOLLEY，B. Tissue-specific expression of the ethylene biosynthetic machinery regulates root growth in maize. Plant Molecular Biology, v.69, p.195-211, 2009. DOI: 10.1007/s11103-008-9418-1.

GEISLER-LEE, J.; CALDWELL, C.; GALLIE, D.R. Expression of the ethylene biosynthetic machinery in maize roots is regulated in response to hypoxia. Journal of Experimental Botany, v.61, p.857-871, 2010. DOI: 10.1093/jxb/erp362. 
GILL, S.S.; TUTEJA, N. Reactive oxygen species and antioxidant machinery in abiotic stress tolerance in crop plants. Plant Physiology and Biochemistry, v.48, p.909-930, 2010. DOI: 10.1016/j.plaphy.2010.08.016.

JOHANSEN, D.A. Plant microtechnique. New York: McGraw-Hill, 1940. 523p.

MALAVOLTA, E. Elementos de nutrição mineral de plantas. São Paulo: Agronômica Ceres, 1980. 251p.

PATEL, P.K.; SINGH, A.K.; TRIPATHI, N.; YADAV, D.; HEMANTARANJAN, A. Flooding: abiotic constraint limiting vegetable productivity. Advances in Plants and Agriculture Research, v.1, article 16, 2014. DOI: 10.15406/ apar.2014.01.00016.

PEREIRA, F.J.; CASTRO, E.M. de; SOUZA, T.C. de; MAGALHÃES, P.C. Evolução da anatomia radicular do milho 'Saracura' em ciclos de seleção sucessivos. Pesquisa Agropecuária Brasileira, v.43, p.1649-1656, 2008. DOI: 10.1590/ S0100-204X2008001200002.

PEREIRA, F.J.; MAGALHÃES, P.C.; SOUZA, T.C. de; CASTRO, E.M. de; ALVES, J.D. Atividade do sistema antioxidante e desenvolvimento de aerênquima em raízes de milho 'Saracura'. Pesquisa Agropecuária Brasileira, v.45, p.451-456, 2010. DOI: 10.1590/S0100-204X2010000500003.

PORTO, B.N.; ALVES, J.D.; MAGALHÃES, P.C.; CASTRO, E.M.; CAMPOS, N.A.; SOUZA, K.R.D.; MAGALHÃES, M.M.; ANDRADE, C.A.; SANTOS, M.O. Calcium-dependent tolerant response of cell wall in maize mesocotyl under flooding stress. Journal of Agronomy and Crop Science, v.199, p. 134-143, 2013. DOI: 10.1111/j.1439-037X.2012.00535.x.

SAIRAM, R.K.; KUMUTHA, D.; EZHILMATHI, K.; DESHMUKH, P.S.; SRIVASTAVA, G.C. Physiology and biochemistry of waterlogging tolerance in plants. Biologia Plantarum, v.52, p.401-412, 2008. DOI: 10.1007/ s10535-008-0084-6.

SEAGO JR, J.L.; MARSH, L.C.; STEVENS, K.J.; SOUKUP, A.; VOTRUBOVÁ, O.; ENSTONE, D.E. A re-examination of the root cortex in wetland flowering plants with respect to aerenchyma. Annals of Botany, v.96, p.565-579, 2005. DOI: 10.1093/aob/mci211.

SOUZA, T.C. de; CASTRO, E.M. de; PEREIRA, F.J.; PARENTONI, S.N.; MAGALHÃES, P.C. Morpho-anatomical characterization of root in recurrent selection cycles for flood tolerance of maize (Zea mays L.). Plant Soil Environment, v.55, p.504-510, 2009.

SOUZA, T.C. de; MAGALHÃES, P.C.; PEREIRA, F.J.; CASTRO, E.M. de; PARENTONI, S.N. Morpho-physiology and maize grain yield under periodic soil flooding in successive selection cycles. Acta Physiologiae Plantarum, v.33, p.1877-1885, 2011. DOI: 10.1007/s11738-011-0731-y.

STEFFENS, B.; STEFFEN-HEINS, A.; SAUTER, M. Reactive oxygen species mediate growth and death in submerged plants. Frontiers in Plants Science, v.4, article 179, 2013. DOI: 10.3389/ fpls.2013.00179.

VANDENBUSSCHE, F.; VASEVA, I.; VISSENBERG, K.; VAN DER STRAETEN, D. Ethylene in vegetative development: a tale with a riddle. New Phytologist, v.194, p.895-909, 2012. DOI: 10.1111/j.1469-8137.2012.04100.x.

VELIKOVA, V.; YORDANOV, I.; EDREVA, A. Oxidative stress and some antioxidant systems in acid rain-treated bean plants: protective role of exogenous polyamines. Plant Science, v.151, p.59-66, 2000. DOI: 10.1016/S0168-9452(99)00197-1.

VITORINO, P.G.; ALVES, J.D.; MAGALHÃES, P.C.; MAGALHĂES, M.M.; LIMA, L.C.O.; OLIVEIRA, L.E.M. de. Flooding tolerance and cell wall alterations in maize mesocotyl during hypoxia. Pesquisa Agropecuária Brasileira, v.36, p.1027-1035, 2001. DOI: 10.1590/S0100-204X2001000800004.

YAMAUCHI, T.; SHIMAMURA, S.; NAKAZONO, M.; MOCHIZUKI, T. Aerenchyma formation in crop species: a review. Field Crops Research, v.152, p.8-16, 2013. DOI: 10.1016/j. fcr.2012.12.008.

ZANANDREA, I.; ALVES, J.D.; DEUNER, S.; GOULART, P. de F.P.; HENRIQUE, P. de C.; SILVEIRA, N.M. Tolerance of Sesbania virgata plants to flooding. Australian Journal of Botany, v.57, p.661-669, 2010. DOI: 10.1071/BT09144.

Recebido em 20 de março de 2015 e aprovado em 15 de julho de 2015 